\title{
Sulfitolytic and keratinolytic potential of Chryseobacterium sp. RBT revealed hydrolysis of melanin containing feathers
}

\author{
Ranjit G. Gurav ${ }^{1,2} \cdot$ Jingchun Tang ${ }^{2} \cdot$ Jyoti P. Jadhav ${ }^{1}$
}

Received: 2 April 2016/ Accepted: 11 June 2016/Published online: 23 June 2016

(c) The Author(s) 2016. This article is published with open access at Springerlink.com

\begin{abstract}
In black feathers, melanin is embedded in keratin matrix that makes feather more resistance to the microbial degradation. Chryseobacterium sp. RBT previously isolated from the poultry waste disposable site revealed strong sulfitolytic and keratinolytic activities. Maximum keratinase activity was observed at $48 \mathrm{~h}$ $\left(89.12 \mathrm{U} \mathrm{ml}^{-1}\right)$ showed $83 \%$ of native black feather degradation. The concentration of free sulfhydryl groups released during degradation was $0.648 \times 10^{-4} \mathrm{M}(12 \mathrm{~h})$, $2.144 \times 10^{-4} \mathrm{M}(96 \mathrm{~h})$, and however, declined on prolong incubation to $1.752 \times 10^{-4} \mathrm{M}(120 \mathrm{~h})$. Melanin was released in the degradation medium after microbial exploitation of black feather. After purification, melanin was dark brown colored powder insoluble in water, $5 \mathrm{M}$ HCL, ethanol, methanol, benzene, chloroform, and acetone; whereas, soluble in $\mathrm{KOH}$ and $\mathrm{NaOH}$. On exposure to oxidizing and reducing reagents feather melanin showed decolorization, while formed a brown precipitate when reacted with $\mathrm{FeCl}_{3}$. The spectroscopic characterization of isolated melanin demonstrated absorption at infra-red region. Similarly, UV-visible scan confirmed that increase in the wavelength progressively declined the absorbance of pigment. The crude keratinase enzyme $(2 \% \mathrm{v} / \mathrm{v})$ produced during degradation showed complete dehairing of goat skin within $20 \mathrm{~h}$.
\end{abstract}

Jyoti P. Jadhav

jpjbiochem@gmail.com

1 Department of Biotechnology, Shivaji University, Kolhapur 416004, India

2 College of Environmental Science and Engineering, Nankai University, Tianjin 300071, China
Keywords 5,5'-Dithio-bis-(2-nitrobenzoicacid) . Chryseobacterium $\cdot$ Dehairing $\cdot$ Keratinase $\cdot$ Melanin

\section{Introduction}

In birds, feather pigmentation mainly depends on the components, such as keratin and melanin, having different refractive indexes. Melanin is widely distributed in plants, animals, and some microbes, although it has been not assigned any specific role in the growth and development but to enhance their survival and competitiveness (Alois and Michael 1986). Chemically melanin was a dark colored, negatively charged, and high molecular weight heterogeneous polymer which was insoluble in most of the aqueous or organic solvents (Nicolaus et al. 1964; Crippa et al. 1989). Melanin is embedded in the $\beta$-keratin matrix arranged in a complex array of feather barbules (Durrer 1986). Besides pigmentation, melanin provides structural rigidity to feathers by cross-linking with proteins and making them more resistant against feather feeding microorganisms and ecto-parasites (Burtt 1986; Goldstein et al. 2004; Gunderson et al. 2008). Wilson et al. (2007) in their study with archaeological contexts found that microbial activity degraded only keratin without affecting the melanin. Similarly, Goldstein et al. (2004) and Gunderson et al. (2008) demonstrated the degradation of melanized feathers using Bacillus licheniformi and B. licheniformi OWU $138 \mathrm{~B}$ and concluded that melanized feathers where unable to biodegrade.

Keratins are the highly specialized fibrous proteins ubiquitous in animals. Feather contains about $90 \%$ keratin protein rich in disulfide bridges which are responsible for making feathers more resistant against common proteases, such as trypsin, pepsin, and papain, thus reduces 
the degradation process in nature (Onifade et al. 1998). However, some biological entities, such as insects (clothes moth larvae, carpet beetles, and chewing lice) and microorganisms (eucarya, bacteria, and archaea), can exploit the keratins. Microbes produce keratinases enzyme to breakdown the keratin and utilize it as a source of carbon, nitrogen, sulfur, and energy for its growth and development (Noval and Nickerson 1959). Previously, Lysobacter NCIMB 9497 (Allpress et al. 2002), Microbacterium sp. (Thys et al. 2004), Xanthomonas maltophilia (de Toni et al. 2002), Stenotrophomonas sp. (Yamamura et al. 2002), Chryseobacterium indologenes TKU014 (Wang et al. 2008), and Serratia sp. HPC 1383 (Khardenavis et al. 2009) were reported as keratin degraders.

Several researchers had isolated genus Chryseobacterium from the poultry carcasses and believed that this bacteria might have been originated from the poultry itself or from the slaughterhouse environment (Hang'ombe et al. 1999). Beer et al. (2005) stated that most of the Chryseobacterium were isolated from the raw chicken portion or whole bird at different stages of meat processing. Vandamme et al. (1994) have stated that genus Chryseobacterium was closely associated with strong proteolytic activity.

Therefore, in present study, previously isolated Chryseobacterium sp. RBT was demonstrated for the degradation of melanin containing native feathers that cannot be degraded by normal microbial flora. This was the first report signifying highest degradation of native black feather within short span of time. The biodegradation efficiency was analyzed by quantifying the keratinase enzyme, soluble protein, amino acid, and free sulfhydryl groups in the medium. During black feather degradation melanin embedded in the feather matrix was released in the medium. This melanin was purified and characterized which has many industrial appplications. Whereas, the crude keratinase enzyme was applied for ecofriendly dehairing of goat skin.

\section{Materials and methods}

\section{Chemicals, black feathers, and goat skin}

Standard melanin (synthetic) and 5,5'-dithio-bis (2-nitrobenzoic acid) were purchased from Sigma-Aldrich, USA. Keratin powder, bovine serum albumin, sodium hydroxide, hydrogen peroxide, ferric chloride, sodium hypochlorite, and potassium hydroxide were obtained from Himedia, India. Solvents, such as ethanol, methanol, chloroform, acetone, benzene, and phenol were procured from Sisco Research Laboratory (SRL), India. All the chemicals and reagents used were of the highest purity and analytical grade. Black feathers of slaughtered domestic fowl (Gallus gallus domesticus) collected from central chicken market, Kolhapur, India were washed, dried, and stored for further studies. Whereas, goat (Capra hircusOsmanabadi breed) skin was obtained from the local meat market in Kolhapur, India.

\section{Microorganism and maintenance}

The Chryseobacterium sp. RBT (genebank accession number GU481093) used in this study was previously isolated from the poultry waste contaminated site. Bacterial culture was routinely subculture and maintained on keratin agar containing $\left(\mathrm{g} \mathrm{l}^{-1}\right)$ : $\mathrm{Na}_{2} \mathrm{HPO}_{4}(6.0), \mathrm{KH}_{2} \mathrm{PO}_{4}(3), \mathrm{NaCl}$ (5), $\mathrm{MgSO}_{4}(0.1)$, keratin powder (1), and agar (25) as a solidifying agent (Gurav and Jadhav 2013a).

\section{Biodegradation of black feathers}

The black feather degradation experiment was carried out in basic salt medium (BSM) having composition $\left(\mathrm{g} \mathrm{l}^{-1}\right)$ : $\mathrm{Na}_{2} \mathrm{HPO}_{4}$ (6.0), $\mathrm{KH}_{2} \mathrm{PO}_{4}$ (3.0), $\mathrm{NaCl}$ (5.0), $\mathrm{MgSO}_{4}(0.1$ ), and native black feathers (10). This medium was inoculated with $0.1 \%(\mathrm{v} / \mathrm{v})$ of Chryseobacterium sp. RBT culture having absorbance 0.92 at $660 \mathrm{~nm}$ and incubated on the orbital shaker (140 rpm) at $37^{\circ} \mathrm{C}$ (Gurav and Jadhav 2013a). The degradation rate was assessed by pulling aliquots at different time intervals to analyze the keratinase activity, free sulfhydryl groups, soluble proteins, and amino acids.

\section{Keratinase assay}

The keratinase activity was determined using pure keratin powder as a substrate (Gurav and Jadhav 2013a). In brief, $1 \mathrm{ml}$ of crude enzyme diluted in tris- $\mathrm{HCl}$ buffer and $1 \mathrm{ml}$ substrate $(0.1 \%$ keratin powder $)$ was incubated at $37{ }^{\circ} \mathrm{C}$ for $10 \mathrm{~min}$. The reaction was terminated by adding $2 \mathrm{ml}$ of $0.5 \mathrm{M}$ trichloro acetic acid (TCA). This reaction mixture was centrifuged, and the absorbance was detected at $280 \mathrm{~nm}$ (UV-1800, Shimadzu, Japan). The enzyme control was treated in the same way except the TCA and was added before incubation. One unit $\left(\mathrm{U} \mathrm{ml}^{-1}\right)$ of keratinase activity was defined as an increase in corrected absorbance by 0.001 units at $280 \mathrm{~nm}$ with control $\mathrm{min}^{-1}$ (Cai et al. 2008) and calculated using formula:

$\mathrm{U}=4 \times n \times A_{280} /(0.01 \times 10)$,

where $n$, dilution rate; 4 , final reaction volume; 10 , incubation time ( $\mathrm{min})$. 


\section{Quantification of free sulfhydryl groups}

The quantification of free sulfhydryl groups released during feather degradation was executed using 5,5'-dithio-bis-(2nitrobenzoic acid), also known as DTNB or Ellman's reagent (Ellman 1959). Sulfhydryl groups in the degradation medium reacted with DTNB and produced a mixture of disulfide and 2-nitro-5-thiobenzoic acid (TNB) which was yellow-colored product measured at $412 \mathrm{~nm}$. In brief, $200 \mu \mathrm{l}$ of cell-free supernatant was added to $2.5 \mathrm{ml}$ of reaction buffer $(0.1 \mathrm{M}$ sodium phosphate, $\mathrm{pH} 8.0$, containing $1 \mathrm{mM}$ EDTA) and $50 \mu \mathrm{l}$ of DTNB solution $\left(4 \mathrm{mg} \mathrm{ml}^{-1}\right.$ ). This reaction mixture was incubated at room temperature for $15 \mathrm{~min}$ and absorbance was recorded at $412 \mathrm{~nm}$ (UV-1800, Shimadzu, Japan). Blank was prepared by adding $2.7 \mathrm{ml}$ of reaction buffer and $50 \mu \mathrm{l}$ of DTNB solution. The free sulfhydryl concentration was calculated using the following formula.

Molar absorptivity $(E)$ is defined as follows:

$E=A / b c$,

where $A$ is the absorbance; $b$ is the path length in centimeters; $c$ is the concentration in $\mathrm{M} \mathrm{l}^{-1}(=\mathrm{M})$.

Solving for concentration gave the following formula:

$c=A / b E$.

The reported molar extinction coefficient of TNB in $0.1 \mathrm{M}$ phosphate, $\mathrm{pH} 8.0,1 \mathrm{mM}$ EDTA was $E=14,150 \mathrm{M}^{-1} \mathrm{~cm}^{-1}$ at $412 \mathrm{~nm}$.

\section{Detection of soluble protein and amino acids}

Soluble protein content of degradation medium was determined by folin-phenol method using BSA as standard (Lowry et al. 1951). Similarly, the amino acids were quantified by ninhydrin method using leucine as standard (Moore and Stein 1957).

\section{Percentage degradation of feather biomass}

The percentage degradation of black feathers was determined on the basis of cell-free dry weight of the residual feathers in the culture broth at the end of experiment (Cortezi et al. 2008).

\section{Separation and purification of the melanin pigment}

Melanin released in the feather degradation medium was filtered through the mesh to separate them from the undigested feathers. The filtrate contained the cell biomass and melanin was further centrifuged, and the resulted pellet was dissolved in $\mathrm{NaOH}$ to make the $\mathrm{pH} 12$ and incubated at room temperature for $60 \mathrm{~min}$. This mixture was then acidified by adding $\mathrm{HCl}$ to precipitate the pigment by decreasing the $\mathrm{pH}$ level to three (Sajjan et al. 2010; Surwase et al. 2013). After centrifugation, a dark blackish brown precipitate of crude melano-protein obtained was washed 4-5 times with doubled distilled water. This brown amorphous material was re-dissolved in $0.1 \mathrm{M} \mathrm{NaOH}$ and deproteinised with $20 \%$ chloroform, and subsequently, the dark brown layer was then separated and re-precipitated with the acid. The obtained pellet was repeatedly washed with methanol and ethanol and was finally lyophilized. Chemical and spectroscopic characterizations were performed with reference to the synthetic standard melanin (Sigma, USA) (Surwase et al. 2013).

\section{Characterization of purified pigment}

\section{Qualitative chemical analysis}

Chemical analysis of the purified pigment was done in parallel to the standard melanin. The pigment solubility was checked in distilled water, ethanol, methanol, chloroform, acetone, benzene, $\mathrm{NaOH}$, and $\mathrm{KOH}$. Similarly, the specific qualitative tests for melanin were performed using $\mathrm{H}_{2} \mathrm{O}_{2}, \mathrm{FeCl}_{3}$, and $\mathrm{NaOCl}$ (Sajjan et al. 2010).

\section{Spectral analysis}

The purified pigment and standard melanin were dissolved in $0.1 \mathrm{M} \mathrm{NaOH}$, and the UV-visible adsorption spectra were recorded between 220 and $800 \mathrm{~nm}$ (Shimadzu, Japan) using $0.1 \mathrm{M} \mathrm{NaOH}$ as blank. The purified feather melanin and standard melanin spectrum were plotted as optical density of compound against the wavelength (Surwase et al. 2013).

\section{FT-IR study}

Fourier transform infra-red spectroscopy (Perkin Elmer, Spectrum 100, USA) of the isolated pigment with reference to the standard melanin was done in the mid IR region of $400-4000 \mathrm{~cm}^{-1}$ with 16 scan speed. The pellet was prepared using spectroscopic grade $\mathrm{KBr}$ (10:90), and analysis was carried out and the changes in \% transmission at different wavelengths were recorded (Sajjan et al. 2010).

\section{Enzymatic leather processing}

The Chryseobacterium sp. RBT produced keratinase enzyme during black feather degradation was applied on goat skin to check the dehairing ability. Crude keratinase $2.0 \%(\mathrm{v} / \mathrm{v})$ was applied on clean goat skin placed in tris$\mathrm{HCl}$ buffer $(50 \mathrm{mM}, \mathrm{pH} 8.6)$ and kept at $37^{\circ} \mathrm{C}$ (Gurav and Jadhav 2013a). The enzyme treated skin samples were 
washed thoroughly under tap water and visually observed for the dehairing, and data was recorded in the form of photographs and time required for skin dehairing.

\section{Statistical analysis}

The data was analyzed by the one-way analysis of variance (ANOVA) with the Tukey-Kramer multiple comparisons test.

\section{Results and discussion}

\section{Degradation of melanin containing feathers}

In the present study, Chryseobacterium sp. RBT hydrolyzed the native black feathers of Gallus gallus domesticus and utilized it as sole source of carbon, nitrogen, and energy. The native black feathers were degraded $(83 \%)$ within $48 \mathrm{~h}$, by releasing melanin embedded in the feather matrix (Fig. 1). Initially, the keratinase enzyme activity was observed at $12 \mathrm{~h}\left(21.9 \mathrm{U} \mathrm{ml}^{-1}\right)$ and was highest at $48 \mathrm{~h}\left(89.12 \mathrm{ml}^{-1}\right)$. However, further incubation until $120 \mathrm{~h}$ $\left(16.20 \mathrm{U} \mathrm{ml}^{-1}\right)$ significantly declined the keratinase activity (Fig. 2). During the degradation process, an increase in the $\mathrm{pH}$ from 7.5 to 8.8 was observed. This tendency of medium alkalinity was attributed due to the deamination reactions leading to release of ammonia from protein, peptides, and amino acids. Such increase in $\mathrm{pH}$ during feather degradation is the important indication of high keratinolytic potential of the microorganisms (Riffel et al. 2003). Similarly, our previous study on poultry feather degradation using Chryseobacterium sp. RBT showed maximum keratinase activity at $\mathrm{pH} 8.6$ (Gurav and

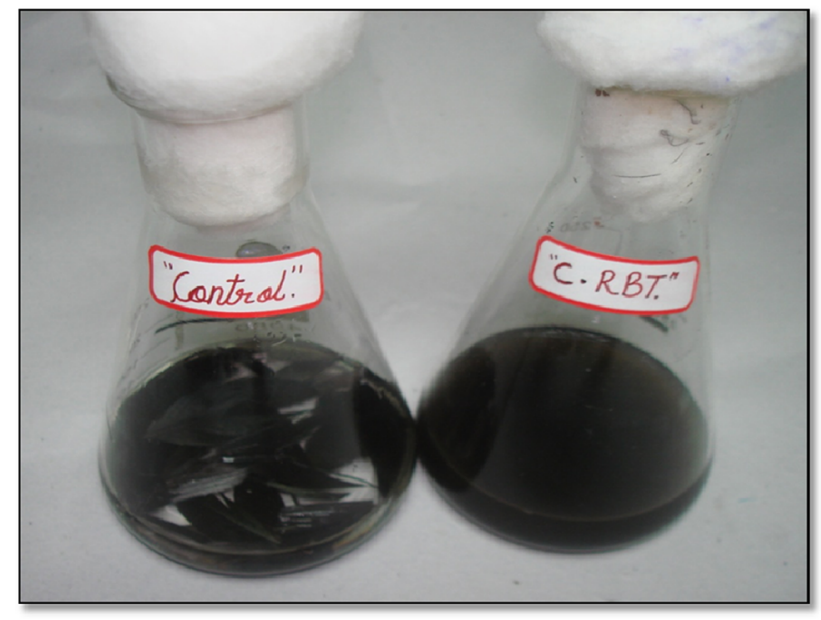

Fig. 1 Degradation of native black feathers by releasing of melanin embedded in the feather matrix. 'Control' without inoculum and ' $\mathrm{C}$. RBT' inoculated with Chryseobacterium sp. RBT (48 h)

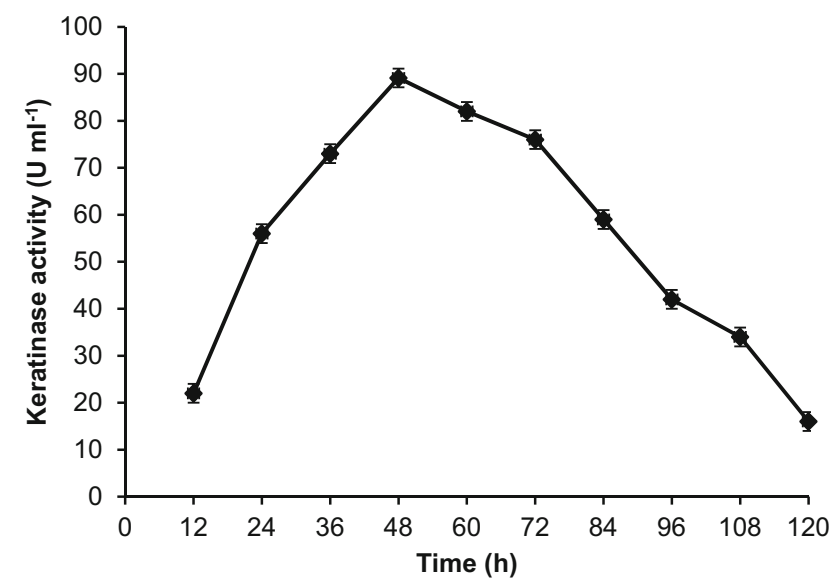

Fig. 2 Keratinase activity $\left(\mathrm{U} \mathrm{ml}^{-1}\right)$ at different time intervals of feather degradation. Data shown as mean $\pm \mathrm{SEM}, n=3$

Jadhav 2013a). On the other hand, medium alkalization may have facilitated the release of melanin embedded in the feather matrix, as it has been well documented by many authors that melanin pigment was likely to be solubilized at alkaline $\mathrm{pH}$.

\section{Determination of free sulphydryl groups}

Loss in the feather biomass was used as a primary and most reliable indicator for microbial keratinolytic abilities (Korniłłowicz-Kowalska 1997). However, other important indicators, such as peptides, amino acids, ammonia, sulfhydryl groups, sulfate excretion, keratinase activity, and medium alkalinisation, are also crucial to study the keratin degradation (Korniłłowicz-Kowalska 1997). Free sulfhydryl groups released during feather degradation were analyzed at different time intervals using 5,5'-dithio-bis (2nitrobenzoic acid) (DTNB). DTNB reagent has high specificity for $-\mathrm{SH}$ groups at neutral $\mathrm{pH}$, high molar extinction coefficient, and short reaction time. The concentration of free sulfhydryl groups in degradation medium was $0.648 \times 10^{-4}$ and $2.144 \times 10^{-4} \mathrm{M}$ at 12 and $96 \mathrm{~h}$, respectively. However, further incubation until $120 \mathrm{~h}$ reduced the content to $1.752 \times 10^{-4} \mathrm{M}$ (Fig. 3).

The cross-linking of protein chains by several disulphide bonds is the most distinctive character of keratins. Such bonding makes the keratin molecule more resistant to mechanical and enzymatic degradation. Many pathways were proposed to explain the microbial breakdown of keratin molecules amongst them one was cleavage of disulfide bonds prior to the proteolytic breakdown. This cleavage of the disulphide bond was carried out by sulfitolytic activities, which was determined by detecting free sulfhydryl groups in the culture media; these results were in agreement with the study of Onifade et al. (1998). The sulfitolytic cleavage of cystine was carried out by means of 


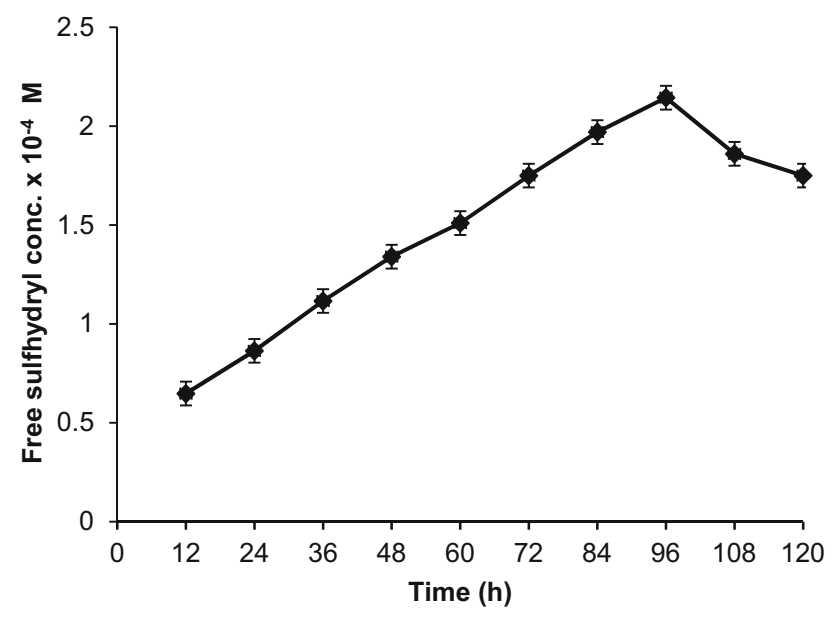

Fig. 3 Analysis of free sulfhydryl groups released during feather degradation. Data shown as mean \pm SEM, $n=3$

excess sulfite released by the microbial cells and was previously studied in filamentous keratinolytic fungi and actinomycetes; however, this pathway was also detected in bacterial degradation (Laba et al. 2015). Such disulphide bonds cleavage during microbial degradation was previously described in Streptomyces pactum (Böckle et al. 1995). Thus, in the present study, Chryseobacterium sp. RBT possesses a strong disulphide-bond breaking ability.

\section{Quantifying the peptides and amino acids}

The Chryseobacterium sp. RBT produces the keratinase enzyme responsible for the degradation of feather keratin into peptides and amino acids. Liberating the protein and amino acid during degradation served as a crucial indicator in feather keratin degradation. The highest soluble protein content was observed at $48 \mathrm{~h}\left(2.98 \mathrm{mg} \mathrm{ml}^{-1}\right)$, whereas further incubation until $120 \mathrm{~h}$ declined the content to $1.14 \mathrm{mg} \mathrm{ml}^{-1}$ (Fig. 4). Similarly, the concentration of free amino acids was evaluated and was enhanced with time; this may be due to the peptides continued to breakdown into amino acids. The maximum free amino acids content was $3.24 \mathrm{mg} \mathrm{ml}^{-1}$ at $84 \mathrm{~h}$ of incubation (Fig. 4). A good correlation between protein, amino acids content, and feather biomass was observed during degradation.

In general, feather degrading microorganisms can either digest keratin through secretion of keratinases or otherwise grow directly on the feathers (Ruiz-Rodríguez et al. 2009). Microbial degradation of the feather biomass results into the hydrolysate rich in peptides, amino acids, and minerals, such as nitrogen, phosphorus, potassium, calcium, magnesium, iron, manganese, zinc, and copper (Gurav and Jadhav 2013b). Soil and foliar application of this feather hydrolysate to banana cultivation created a promising approach for nourishing the soil and also stimulated the

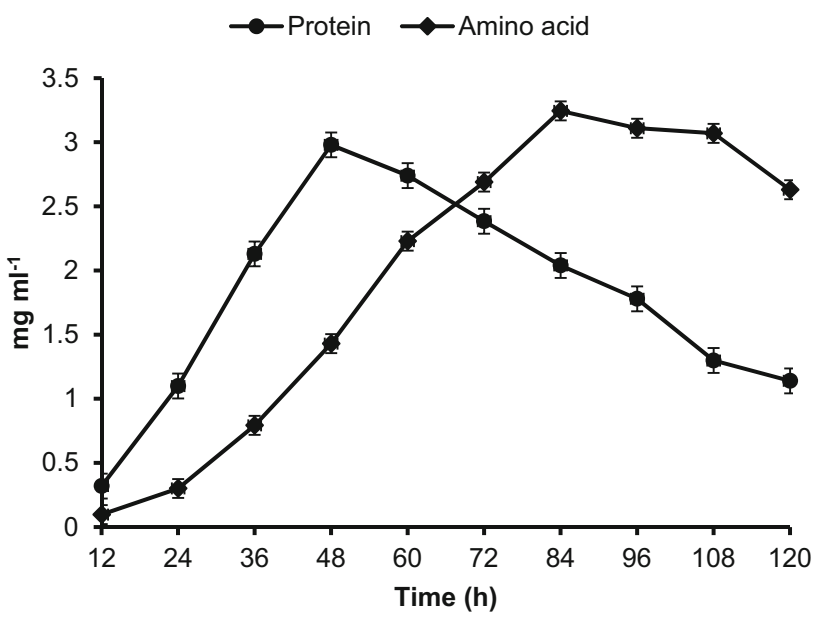

Fig. 4 Protein and amino acid contents of degradation broth with time. Data shown as mean \pm SEM, $n=3$

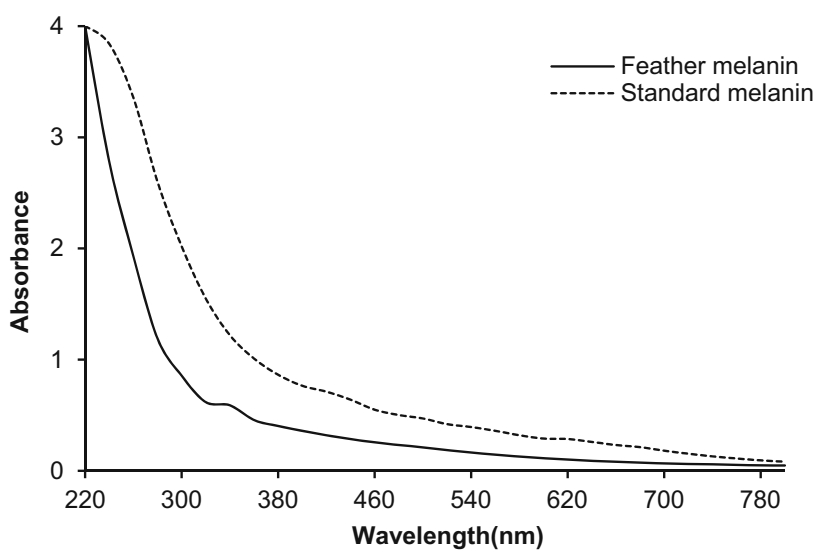

Fig. 5 UV-visible spectral analysis of feather melanin $(-)$ and standard melanin (‥) pigment

production of banana fruits rich in health beneficial compounds, such as antioxidants (Gurav and Jadhav 2013b).

\section{Characterization of feather melanin}

On purification obtained blackish brown colored pigment was insoluble in water, $5 \mathrm{M} \mathrm{HCL}$, ethanol, methanol, benzene, chloroform, acetone, and soluble in $\mathrm{KOH}$ and $\mathrm{NaOH}$. Whereas pigment showed decolorization after reacting with the oxidizing and reducing reagents, such as $\mathrm{NaOCl}$ and $\mathrm{H}_{2} \mathrm{O}_{2}$. Similarly, pigment produced a brown precipitate when reacted with $\mathrm{FeCl}_{3}$. All the results were compared and found identical with the synthetic standard melanin (Sigma).

\section{Spectroscopic analysis of the pigment}

The UV-visible absorption spectrum of synthetic and purified feather melanin is described in Fig. 5. The 
absorption was highest in UV region at 200-300 nm, but significantly declined towards the visible region, which was the characteristic property of melanin. This phenomenon was due to the presence of very complex conjugated arrangement in the melanin. A linear relationship between $\log$ absorbance and wavelength from 400 to $800 \mathrm{~nm}$ was observed, which was one of the most important criteria in melanin characterization. Such distinctive straight line with negative slope was demonstrated earlier in melanin produced by microorganisms (Sajjan et al. 2010; Surwase et al. 2013).

The FT-IR spectroscopy was preferred for additional characterization of the feather pigment. FT-IR was the most revealing, well-resolved, and non-destructive method, providing information on functional groups and detailed structural analysis (Sajjan et al. 2010; Surwase et al. 2013). The IR spectrum of feather melanin and standard melanin showed high degree of similarity with each other (Fig. 6). This characteristic property of the IR spectrum of melanin pigment was analogous with many earlier reports.

The obtained feather melanin could be used as an ingredient in photo protective creams, sunscreen lotions, bioinsecticidal preparations, removal of the heavy metals found in the environment, and protective against reactive oxygen and reactive nitrogen species (Sajjan et al. 2010; Surwase et al. 2013).

\section{Leather dehairing}

The crude keratinase enzyme after applying on goat skin showed effective dehairing within $20 \mathrm{~h}$ (Fig. 7). Mechanical forces were not needed in enzymatic treated skin to remove the hair. However, the untreated goat skin showed intact hair with no hair releasing signs even by plucking with the forceps.

Currently, lime and sodium sulphide is widely applied for dehairing of the skin however; such chemicals are

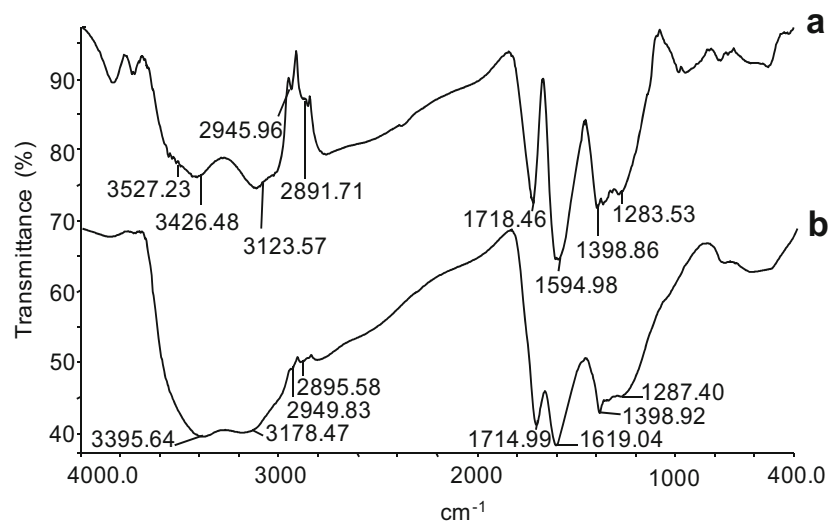

Fig. 6 FT-IR spectrum of the melanin pigments: a synthetic melanin, b feather melanin

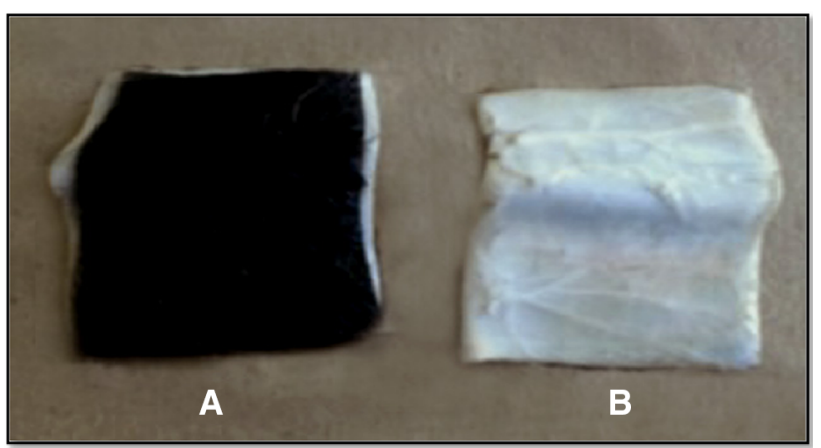

Fig. 7 Enzymatic dehairing of goat skin: a without treatment, b crude enzyme treated $(20 \mathrm{~h})$

hazardous to humans and the environment (Malathi and Chakraborty 1991). In the enzymatic dehairing process, a selective breakdown of keratin tissue in hair follicle was observed which releases the intact hair without affecting the tensile strength of leather and the removed hair can be further used for vale addition (Macedo et al. 2005).

\section{Conclusion}

Chryseobacterium sp. RBT degraded the native black feathers within short span of time liberating melanin embedded in the feathers matrix. This bacterium exhibited both keratinolytic as well as sulfitolysis activities that facilitated the breakdown of protein and di-sulphide bonds in keratin. The isolated feather melanin showed similar physical and chemical properties with synthetic melanin which could be exploited for many industrial applications. Whereas the crude keratinase enzyme could be employed as an effective and ecofriendly alternative in leather processing. Results of this research work can guide and lead to the anticipated path for biotechnological interventions to produce the value added products from the waste feather biomass.

Acknowledgments R.G. Gurav wishes to express sincere gratitude to Science and Engineering Research Board (SERB), New Delhi, India for Young Scientist (PI) award and Nankai University, Tianjin, China for the Post-Doctoral research fellowship.

\section{Complaince with ethical standards}

Conflict of interest The authors declare that they have no conflict of interest.

Open Access This article is distributed under the terms of the Creative Commons Attribution 4.0 International License (http:// creativecommons.org/licenses/by/4.0/), which permits unrestricted use, distribution, and reproduction in any medium, provided you give appropriate credit to the original author(s) and the source, provide a link to the Creative Commons license, and indicate if changes were made. 


\section{References}

Allpress J, Mountain G, Gowland P (2002) Production, purification and characterization of an extracellular keratinase from Lysobacter NCIMB 9497. Lett Appl Microbiol 34:337-342

Alois B, Michael H (1986) Biosynthesis and functions of fungal melanins. Annu Rev Phytopathol 24:411-451

Beer H, Hugo C, Jooste P, Willems A, Vancanneyt M, Coenye T, Peter A (2005) Chryseobacterium vrystaatense sp. nov., isolated from raw chicken in a chicken processing plant. Int J Syst Evol Microbiol 55:2149-2153

Böckle B, Galunski B, Müller R (1995) Characterization of a keratinolytic serine proteinase from Streptomyces pactum DSM 40530. Appl Environ Microbiol 61:3705-3710

Burtt E (1986) An analysis of physical, physiological and optical aspects of avian coloration with emphasis on wood-warblers. Ornithol Monogr 38:1-126

Cai C, Lou B, Zheng X (2008) Keratinase production and keratin degradation by a mutant strain of Bacillus subtilis. J Zhejiang Univ Sci B 9:60-67

Cortezi M, Cilli E, Contiero J (2008) Bacillus amyloliquefaciens: a new keratinolytic feather degrading bacteria. Curr Trends Biotechnol Pharm 2:170-177

Crippa P, Horak V, Prota G, Svoronos P, Wolfram L (1989) Chemistry of melanins. The alkaloids, vol 36. Academic press, New York, pp 253-323

de Toni C, Richter M, Chagas J, Henriques J, Termignoni C (2002) Purification and characterization of an alkaline serine endopeptidase from a feather degrading Xanthomonas maltophilia strain. Can J Microbiol 48:342-348

Durrer H (1986) The skin of birds: colouration. In: Bereiter-Hahn J, Matoltsy A, Sylvia Richards K (eds) Biology of the integument. Vertebrates, Springer, Berlin, Germany 2:239-247

Ellman G (1959) Tissue sulfhydryl groups. Arch Biochem Biophys 82:70-77

Goldstein G, Flory K, Browne B, Majid S, Ichida J, Burtt E (2004) Bacterial degradation of black and white feathers. Auk 121:656-659

Gunderson A, Frame A, Swaddle J, Forsyth M (2008) Resistance of melanized feathers to bacterial degradation: is it really so black and white. J Avian Biol 39:539-545

Gurav R, Jadhav J (2013a) Biodegradation of keratinous waste using Chryseobacterium sp. RBT isolated from soil contaminated by poultry waste. J Basic Microbiol 53:128-135

Gurav R, Jadhav J (2013b) A novel source of bio-fertilizer from feather biomass for banana cultivation. Environ Sci Pollut Res 20:4532-4539

Hang'ombe B, Sharma N, Skjerve E, Tuchili L (1999) Isolation of bacteria during processing of chicken carcasses for the market in Lusaka, Zambia. Vet Arhiv 69:191-197

Khardenavis A, Kapley A, Purohit H (2009) Processing of poultry feathers by alkaline keratin hydrolyzing enzyme from Serratia sp. HPC 1383. Waste Manag 29:1409-1415

Korniłłowicz-Kowalska T (1997) Studies on the decomposition of keratin wastes by saprotrophic micro fungi. P.I. criteria for evaluating keratinolytic activity. Acta Mycol 32:51-79

Laba W, Choinska A, Rodziewicz A, Piegza M (2015) Keratinolytic abilities of Micrococcus luteus from poultry waste. Braz J Microbiol 46:691-700
Lowry O, Rosebrough N, Farr A, Randall R (1951) Protein measurement with the folin-phenol reagent. J Biol Chem 193:265-275

Macedo A, Beys da Silva W, Gava R, Driemeier D, Pegas Henriques J, Termignoni C (2005) Novel keratinase from Bacillus subtilis S14 exhibiting remarkable dehairing capabilities. Appl Environ Microbiol 71:594-596

Malathi S, Chakraborty R (1991) Production of alkaline protease by a new Aspergillus flavus isolate under solid substrate fermentation, conditions for use as a depilation agent. Appl Environ Microbiol 57:712-716

Moore S, Stein W (1957) A modified ninhidrin reagent for the photometric determination of amino acids and related compounds. J Biol Chem 211:907-913

Nicolaus R, Piattelli M, Fattorusso E (1964) The structure of melanins and melanogenesis IV, on some natural melanins. Tetrahedron 20:1163-1172

Noval J, Nickerson W (1959) Decomposition of native keratin by Streptomyces fradiae. J Bacteriol 77:251-263

Onifade A, Al-Sane N, Al-Musallam A, Al-Zarban S (1998) A review: potentials for biotechnological applications of keratindegrading microorganisms and their enzymes for nutritional improvement of feathers and other keratins as livestock feed resources. Bioresour Technol 66:1-11

Riffel A, Lucas F, Heeb P, Brandelli A (2003) Characterization of a new keratinolytic bacterium that completely degrades native feather keratin. Arch Microbiol 179:258-265

Ruiz-Rodríguez M, Valdivia E, Soler Juan J, Martín-Vivaldi M, Martín-Platero A, Martínez-Bueno M (2009) Symbiotic bacteria living in the hoopoes uropygial gland prevent feather degradation. J Exp Biol 212:3621-3626

Sajjan S, Kulkarni G, Yaligara V, Kyoung L, Karegoudar T (2010) Purification and physiochemical characterization of melanin pigment from Klebsiella sp. GSK J Microbiol Biotechnol 20:1513-1520

Surwase S, Jadhav S, Phugare S, Jadhav J (2013) Optimization of melanin production by Brevundimonas sp. SGJ using response surface methodology. 3 Biotech 3:187-194

Thys R, Lucas F, Riffel A, Heeb P, Brandelli A (2004) Characterization of a protease of a feather degrading Microbacterium species. Lett Appl Microbiol 39:181-186

Vandamme P, Bernardet J, Segers P, Kersters K, Holmes B (1994) New perspectives in Bergeyella gen. nov. and Empedobacter nom. rev. Int J Syst Evol Microbiol 44:827-831

Wang S, Hsu W, Liang T, Yen Y, Wang C (2008) Purification and characterization of three novel keratinolytic metalloproteases produced by Chryseobacterium indologenes TKU014 in a shrimp shell powder medium. Bioresour Technol 99:5679-5686

Wilson A, Dodson H, Janaway R, Pollard A, Tobin D (2007) Selective biodegradation in hair shafts derived from archaeological, forensic and experimental contexts. $\mathrm{Br} \mathrm{J}$ Dermatol 157:450-457

Yamamura S, Morita Y, Hasan Q, Yokoyama K, Tamiya E (2002) Keratin degradation, a cooperative action of two enzyme s from Stenotrophomonas sp. Biochem Biophys Res Commun 294:1138-1143 